\title{
Postmenopausal women with medically treated diabetes have increased risk of lung cancer
}

\section{Michael Leitzmann}

\subsection{6/eb-2012-101004}

Department of Epidemiology and Preventive Medicine, Regensburg University, Regensburg, Germany

Correspondence to: Dr Michael Leitzmann Department of Epidemiology and Preventive Medicine, Regensburg University, Franz-Josef-Strauss-Allee 11, Regensburg 93053, Germany; michael.leitzmann@klinik.uniregensburg.de

\section{Commentary on: Luo J, Chlebowski R, Wactawski-Wende J, et al. Diabetes and lung cancer among postmenopausal women. Diabetes Care 2012;35:1485-91.}

\section{Implications for practice and research}

- Lung cancer may potentially be added to the list of cancers directly related to diabetes or insulin treatment.

- Current evidence is insufficient to consider lung cancer risk as the basis for selecting appropriate diabetes therapy.

- Diabetes patients who require insulin therapy for metabolic control should continue to be treated with insulin.

\section{Context}

Considerable epidemiological evidence suggests that type 2 diabetes is associated with increased risk of developing various types of malignancies, most notably cancers of the liver, pancreas, endometrium, colorectum, breast and bladder. In contrast, type 2 diabetes has previously not been widely thought to be linked with lung cancer. ${ }^{1}$ The relation of diabetes to lung cancer is complex and the study by Luo and colleagues addresses a number of important methodological challenges in this research area.

\section{Methods}

In a large prospective cohort study of 145765 postmenopausal women from the U.S Women's Health Initiative, the authors examined the relationships of type 2 diabetes and diabetes therapy to lung cancer risk. Detailed information on diabetes status and diabetes therapy was assessed using self-reports at study baseline and during follow-up. Women with diabetes were grouped into four categories according to diabetes treatment type: (1) no diabetes medication, (2) metformin alone, (3) other oral medication alone and (4) insulin (alone or in combination with oral medication). Lung cancer incidence was also based on the participants' self-report and was subsequently confirmed by a review of medical records and pathology reports.

\section{Findings}

During 11 years of follow-up, 2257 incident cases of lung cancer were ascertained. The multivariable HR of lung cancer comparing women with treated type 2 diabetes to those without diabetes was 1.27 (95\% CI 1.02 to 1.59). The positive association between treated diabetes and lung cancer was particularly strong among women requiring insulin treatment $(\mathrm{HR}=1.71,95 \% \mathrm{CI} 1.15$ to 
2.53). The finding of an increased lung cancer risk among patients with diabetes, or among them treated with insulin, is consistent with several recent studies on this topic. ${ }^{2-4}$

\section{Commentary}

A notable strength of this study is the collection of detailed information on potential confounding factors. This is important because the biological mechanisms through which diabetes affects lung cancer may operate through shared risk factors, such as smoking or a poor diet. A further positive asset of the study is the availability of data on duration of diabetes as a predictor of lung cancer risk. While no overall association was found with diabetes duration, lung cancer risk was suggestively greater during the first 6 years after diabetes diagnosis ( $\mathrm{HR}=1.23,95 \% \mathrm{CI} 0.93$ to 1.61$)$ than 6 years or more after diabetes diagnosis ( $\mathrm{HR}=0.98,95 \% \mathrm{CI} 0.74$ to 1.29 ).

It is critical to consider the possibility of detection bias because heightened medical surveillance among diabetics may have resulted in lung cancers being detected more frequently or diagnosed earlier than in non-diabetics, thereby spuriously increasing lung cancer risk, particularly during the initial period of follow-up. There is previous epidemiological evidence of potential detection bias in the assessment of lung cancer risk in diabetics, with a $170 \%$ increased risk of lung cancer among diabetics in the initial 3-month follow-up period following a new diagnosis of diabetes, which subsequently became null after the initial 3-month time window. $^{5}$
An additional methodological issue is confounding by indication. Insulin is typically administered to patients who have not responded to oral medication or those who have contraindications to glucose-lowering drugs, such as renal, hepatic or cardiovascular disease. Thus, there is potential for confounding by indication if failure of oral medication or the development of ill health is linked to risk factors for lung cancer (such as smoking) or preclinical lung cancer. A further methodological concern is the possibility of reverse causation, which could occur if lung cancer worsens glycaemic control prior to diagnosis, thereby necessitating a change from oral drugs to insulin therapy.

Competing interests None.

\section{References}

1. Giovannucci E, Harlan DM, Archer MC, et al. Diabetes and cancer: a consensus report. Diabetes Care 2010;33:1674-85.

2. Seshasai SR, Kaptoge S, Thompson A, et al. Diabetes mellitus, fasting glucose, and risk of cause-specific death. $N$ Engl J Med 2011;364:829-41.

3. Bodmer M, Becker C, Jick SS, et al. Metformin does not alter the risk of lung cancer: a case-control analysis. Lung Cancer 2012;78:133-7.

4. Carstensen B, Witte DR, Friis S. Cancer occurrence in Danish diabetic patients: duration and insulin effects. Diabetologia 2012;55:948-58.

5. Johnson JA, Bowker SL, Richardson K, et al. Time-varying incidence of cancer after the onset of type 2 diabetes: evidence of potential detection bias. Diabetologia 2011;54:2263-71. 


\section{ERN Postmenopausal women with medically treated diabetes have increased risk of lung cancer}

Michael Leitzmann

Evid Based Nurs 2013 16: 83-84 originally published online November 24, 2012

doi: 10.1136/eb-2012-101004

Updated information and services can be found at:

http://ebn.bmj.com/content/16/3/83

These include:

References This article cites 6 articles, 2 of which you can access for free at: http://ebn.bmj.com/content/16/3/83\#BIBL

Email alerting service

Receive free email alerts when new articles cite this article. Sign up in the box at the top right corner of the online article.

Topic

Articles on similar topics can be found in the following collections

Collections

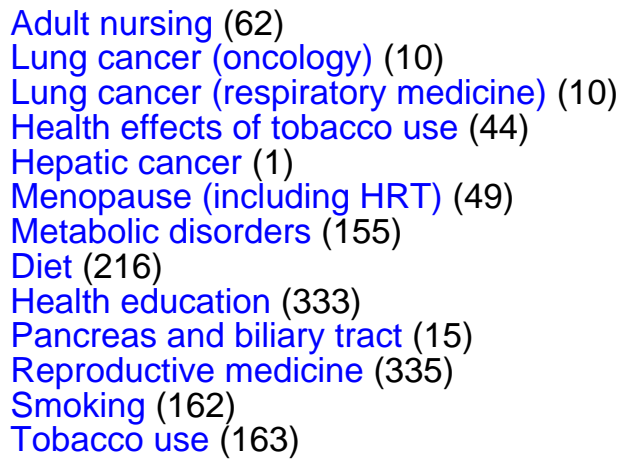

\section{Notes}

To request permissions go to:

http://group.bmj.com/group/rights-licensing/permissions

To order reprints go to:

http://journals.bmj.com/cgi/reprintform

To subscribe to BMJ go to:

http://group.bmj.com/subscribe/ 